involved on work showing how the details of fission are dominated by shell effects and this work was described in a talk by R. Balian. Some of the ways fission is contributing to the main stream through the spectroscopy of the shape isomers were discussed by $\mathrm{S}$. Bjornholm. One of the highlights of the fission contributions was the experiment carried out at Munich in which the E2 internal conversion lines of the ground state rotational band of the shape isomer have been observed and show the expected larger moment of inertia.

It was the calculations of the nuclear potential energy surface which led to the speculations on super heavy elements and the possibility of their formation in heavy ion reactions. Swiatecki, in a talk linking fission and heavy ion reactions, emphasized the relevance of the information obtained on the shape of the nuclear potential energy surface to the possibility of formation of super heavy elements and the critical need for knowledge of nuclear viscosity.

A different approach to the nucleus is involved in the remaining topic covered by the conference - nuclear physics above $100 \mathrm{MeV}$, in which high energy projectiles or mesons are used to probe the fine structure of nuclei. It is from these experiments, as Wilkinson emphasized in a closing talk, that we are getting evidence that the nucleus really is made from neutrons and protons. There were contributions showing the effect of the 3-3 resonance in pion-nucleus scattering and in photo-meson production in nuclei, but the inelastic electron scattering and the $p, 2 p$ experiments which reveal the low-lying bound levels still appear to disagree on the position of the lowest s level.

This conference showed that heavy ion and high energy approaches to the nucleus are beginning to take us away from the traditional preoccupation with light ion reactions and the few nucleons at the top of the Fermi sea. It was successful and timely in bringing together these developing fields and in highlighting areas where, with appropriate facilities, our understanding of the nucleus will be enriched.

\title{
Physics of Semiconductors
}

\section{5-29 July 1972, Warsaw, Poland}

The International Conference on the Physics of Semiconductors was held in Warsaw, 25-29 July 1972, as the eleventh in the series of biannual international conferences, which are supposed to summarize two-year periods in the development of semiconductor physics.

The conference was organized by the Institute of Physics of the Polish Academy of Sciences together with the University of Warsaw and sponsored by the International Union of Pure and Applied Physics.

The organizers received more than 450 contributed papers, of which they could accept less than one-third. The invited speakers and subjects were chosen on the basis of suggestions sent to us by the members of both the International and the Polish
Programme Committees. The seven plenary invited papers should give some idea of what, we felt, are the most important subjects in the current development of semiconductor physics. A.L. Efros of loffe Institute in Leningrad spoke on Low Temperature Conductivity of Strongly Compensated Semiconductors, T. Kasuya of Thoku University in Sendai on New Aspects of the Electronic Properties of Magnetic Semiconductors, W. Paul of Harvard University on Current Status of Some Basic Problems in Amorphous Semiconductors, I. Solomon of Ecole Polytechnique in Paris on Spin-Dependent Properties of Semiconductors, D.C. Tsui of Bell Laboratories on Quantum Eifects in the Semiconductor Surface Layer, and W. Zawadzki of the Institute of Physics in Warsaw on Electron Scattering and Transport Phenomena in Small-Gap Semiconductors.

The conference was attended by more than 600 participants. Among the biggest delegations were : Poland 110 , USA and USSR - 80 each, France and German Federal Republic - 50 each, Czechoslovakia and German Democratic Republic - 30 each, Great Britain and Japan - 25 each.

The general opinion was that the conference was a success. The participants complimented the programme, as being truly international and wellorganized both in time and in the choice of invited papers.

The next conference will be held in Stuttgart in 1974, and will be organized by Dr. O.G. Folberth, IBM Component Development Laboratory, Schönaicherstr. 220, D-703 Böblingen, Fed. Rep. of Germany.

\section{J. Kolodziejczak}

\section{ESSDERC 1972}

\section{1-15 September 1972, Lancaster, UK}

The Second European Solid State Device Research Conference was held at the University of Lancaster, England, from 11-15 September 1972, and was attended by over 300 scientists from 19 countries. This series of conferences has become established by combining the German and British meetings on the same topic, and like them features a small number of invited lectures and a large number of ten-minute contributed papers. This year the invited talks were by E. Ash (Integrated Optics), M. Bernard (NonLinear Optical Susceptibilities), J. Collins (Ferrimagnetic Film Microwave
Devices), W. Merz (Ferroelectric Applications), E.G.S. Paige (Acoustic Surface Wave Devices) and H. Queisser (Semiconductors in the Relaxation Regime). All reached an unusually high standard, but Hans Queisser's contribution must be singled out as exceptional. A stranger entering the hall during the applause at the end might well have thought that a US Presidential candidate was being nominated! The talk was concerned with the behaviour of semiconductors when the carrier lifetime was shorter than the dielectric relaxation time, a condition that causes most of our standard assumptions to become invalid, and that turns conventional teaching on its head. One feature of the other invited talks that aroused some comment was the avoidance of semiconductor topics. Most solid state device conferences in the past have been heavily weighted towards semiconductors, and it was interesting to note how so many other areas are now proving ripe for exploitation. A special evening discourse by $W$. Shockley on the early history that lay behind the invention of the transistor entertained a large audience. For an hour or so, they were taken back twenty-five years, and treated to a well-prepared and documented exposition, bringing in characters familiar and unfamiliar, and tracing their subsequent fates. 
Strict refereeing by a knowledgeable programme committee had been unable to fault nearly 100 contributed needed to accommodate them. Fortunately, Lancaster has suitable lecture theatres adjacent to each other, and it was relatively easy to commute. The organizers consistently allotted the Topics covered included Microwave Devices, Schottky Barriers, Surface terial Processing, Liquid Crystals, Electroluminescence and Glassy Switches, but most excitement was generated by a paper from M.F. Tompsett, in which he showed a colour TV picture obtained using charge-coupled image-sensing arrays. papers, and two parallel sessions were more popular session to the smaller theatre, but there were few complaints. Acoustic Waves, Semiconductor Ma-

The extra-curricular activities were also educational. Those who took the afternoon outing towards the Lake District saw one lake, one stately home, and one coach crash. At the dinner at the Wintergarden in Morecambe, the guest speaker was F.J.M. Laver, the U.K. Post Office Board Member for Data Processing, and both his speech and the menu were excellent. We are told that the dozen ladies who came with their husbands made good use of their time, with visits arranged to Blackpool, the Lake District and Lancaster Castle.

ESSDERC 1973 it to be held in Munich from 18-21 September 1973, and the Chairman will be $\mathrm{H}$. Weiss, Siemens Research Laboratories, Munich.

C. Hilsum

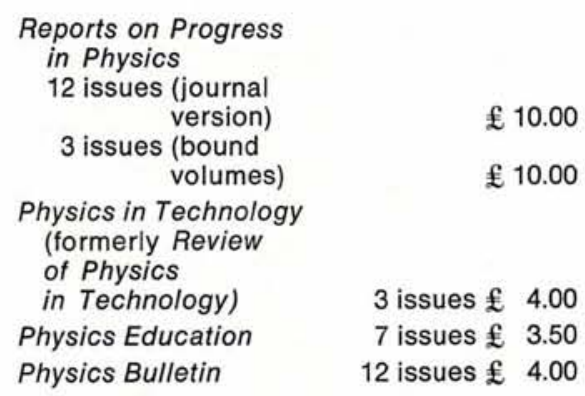

Furthers details and sample copies

24 issues $£ 12.00$ 18 issues $£ 10.00$

12 issues £ 6.00

Instruments

Offprints of all letters in Journal of Physics $A-D$ and $F$

Physics in Medicine and Biology of these journals may be obtained from M. Grover, Circulation Manager, The Institute of Physics, Netherton House, 23 Marsh Street, Bristol BSI $4 B T, U K$ to whom subscriptions should also be sent. 12 issues \& 6.00

12 issues £ 8.00

12 issues £ 8.00

\section{Correction}

We apologie to A. Baldin (Dubna) for omission of his name from the Board of the High Energy and Particle Physics Division in the November 1972 issue, page 4.

\section{Individual Ordinary Members}

The following have been accepted as Individual Ordinary Members of EPS:
E. Arimondo, Pisa
O.-M. Bilaniuk, Grenoble
A. Blaauw, Hamburg
M. Boon, Carouge-Geneva
I. Borchert, Göttingen
A. Bril, Nuenen
D. Callebaut, Dendermonde
E. Carome, Cleveland
P.K. Carroll, Dublin
M.H. Checinska, Warsaw
P. Cicmanec, Bratislava
R. Cusack, Collex-Bossy
J.W. Darewych, Meudon
J. Darville, Jambes
O.J. Eder, Vienna
J.W.R. Fennema, Hilversum
G. Foekema, Utrecht
E. Gotsman, Tel Aviv
D. Hahn, Berlin
W. Hering, Garchiny

\author{
J. Hevesi, Szeged \\ H.E. Hoenig, Frankfurt/Main \\ A. Hrynkiewicz, Krakow \\ F. lachello, Turin \\ G. Imbusch, Galway \\ B. Jezowska-Trzebiatowska, \\ Wroclaw \\ Q. Kessel, Storrs \\ I. Ketskeméty, Szeged \\ T.A. King, Manchester \\ H. Knoepfel, Frascati \\ L. Kozma, Szeged \\ W. Kündig, Zürich \\ W. Kern, Berlin \\ A. Klemm, Mainz \\ J. Lang, Szeged \\ J. Madar, Bratislava \\ Ch. Maslen, Wimborne \\ M. Miesowicz, Krakow \\ K. Moriarty, Egham
}

New Books from North-Holland

\section{Many-Body Problems}

By G.E. BROWN, NORDITA, Copenhagen, Denmark, and State University of New York, Stony Brook, U.S.A. 1972. 240 pages

Dfl. 40.00 (ca. $\$ 12.50$ ) Paperback

Contents : Self-Consistent Fields. Occupation Number Representations. Perturbation Theory. Excitations and Green's Functions. RandomPhase Approximation. The Landau Theory of Fermi Liquids. Phonons and Electrons. Theory of Superconductivity.

\section{Polarons in lonic Crystals} and Polar Semiconductors

Proceedings of the 1971 Antwerp Advanced Study Institute on Fröhlich Polarons and Electron-Phonon Interactions in Polar Semiconductors.

Edited by JOZEF T. DEVREESE, University of Antwerp, Belgium.

1972. 807 pages

Dfl. 140.00 (ca. $\$ 43.75$ )

Contains the proceedings of a meeting held to review the progress made in polaron physics since 1962. The major theoretical and experimental developments dealt with in this book include: magneto-optical properties (with applications relating to $I I-\mathrm{VI}$ and $I I I-\mathrm{V}$ semiconductors): internal excited states (resonances) of polarons and their role in the optical and magneto-optical properties of ree and bound polarons (applications to ree andides, thallous-halides and alingerhalides) ; transport properties (including high field effects) with an extension of the KUBO formation; polarons in degenerate semiconductors; piezo-polarons; acousto-polarons; small-polarons (transition metal oxides) excitons; effects of nonparabolicity of bands: alternative formulations of the theory.

With contributions from leading physicists in the field, the book is intended for graduate physicists with a background in solid state physics. Many tables are given which relate physical constants to polaron properties.

\section{Principles and Application of Magnetic Cooling}

By R.P. HUDSON, National Bureau of Standards, Washington.

NORTH-HOLLAND SERIES IN LOW TEMPERATURE PHYSICS, Vol. 2

1972. 248 pages

Dfl. 60.00 (ca. \$ 18.75) Paperback

Contents : Historical introduction. Principles of magnetic cooling. Paramagnetism. Experimental procedure. Properties of individual substances. Nuclear magnetism. Appendices: Effects of a crystal field splitting. Schottkyeffect anomaly in heat capacity. Singlet states and the quenching of orbital angular momentum. Kramers' theorem. Generation of matrix elements of angular momentum operators. High temperature approximations using principle of invariance of diegonal sum, principle. Vapour pressure tables for ${ }^{3} \mathrm{He}$ and ${ }^{4} \mathrm{He}$.

\section{NORTH HOLLAND}

P.O. Box 1270 - Amsterdam - The Netherlands Sole distributors for the U.S.A. and Canada: American Elsevier Publishing Company, Inc. 52 Vandertilt Avenue, New York, N.Y. 10017. 